\title{
Effect of constraint on schedule-induced drinking
}

\author{
J. D. KEEHN and ARNIE MAYERS \\ York University, Atkinson College, Downsview, Ontario M3J 2R7, Canada
}

\begin{abstract}
Schedule-induced drinking was studied with four white rats reinforced with dry food pellets at fixed 1-min intervals in 5-h experimental sessions. When drinking was permitted for only $5 \mathrm{~min} / \mathrm{h}$, draught durations were longer and more frequent than in matched periods in sessions when water was always available. Rates of eating were approximately equal under both conditions.
\end{abstract}

Laboratory rats normally drink in the vicinities of meals (Kissileff, 1969). Exact occasions of eating and drinking are apparently random (Premack, 1965), but as constraints are placed on eating, so drinking occurs more predictably. With small pellets of dry food scheduled intermittently up to $2-3$ min apart, post pellet drinking is virtually $100 \%$ and is sufficiently durable in most experimental subjects to cause polydipsia (Falk, 1961).

Schedule-induced drinking results when eating by hungry rats is interrupted (Keehn \& Colotla, 1971), and draught size is directly related to food deprivation (Falk, 1969; Freed \& Hymowitz, 1972; Keehn, 1979) and to the magnitude of the neighboring meal (Flory, 1971; Hawkins, Schrot, Githens, \& Everett, 1972; Rosenblith, 1970). Water deprivation is unnecessary to establish the phenomenon (Brush \& Schaeffer, 1974), but effects of interrupting schedule-induced drinking once it begins are not known. Here, we show that if schedule-induced drinking is occasionally prevented during intermittent feeding, then subsequent drink draughts are augmented.

\section{METHOD}

\section{Subjects}

Four naive male Wistar rats, supplied by High Oak Ranch, Ontario, were used. They were maintained in individual cages at $85 \%$ of 100 -day-old body weights and were about 120 days old when the experiment began. Mean running weights for Animals A6, A7, A8, and A9, respectively, were 333.6, 307.9, 324.8 , and $305.4 \mathrm{~g}$. Water was always available in home cages, and also in experimental sessions as described below.

\section{Apparatus}

Two standard $29 \times 23.5 \times 19 \mathrm{~cm}$ Grason-Stadler two-bar rat chambers (Type E3125B) mounted in ventilated soundattenuating chests were the experimental areas. In each chamber, the bar beside the door was removed and its housing was covered with a metal plate. A force of $.19 \mathrm{~N}$ on the remaining bar activated relay scheduling and recording equipment in an adjoining room.

A water bottle, sometimes empty, was attached to each chamber door such that the outlet tube was $5 \mathrm{~cm}$ above floor level and $18 \mathrm{~cm}$ from the food magazine. Licks on these tubes were counted and recorded on Gerbrands cumulative recorders via Grason-Stadler drinkometers, and volumes of water consumed per session were measured directly from graduations on the water bottles.

\section{Procedure}

Subjects were adapted to the experimental chambers and then trained by successive approximations to barpress for 45-mg Noyes pellets as reinforcers. Training was accomplished in a single session with each animal, in which it received 100 reinforcers. Then followed five 5-h control sessions in which each barpress was reinforced until up to 300 reinforcers were secured. Water was available for the whole of these 5-h sessions, and fluid intakes were measured as baseline values per 300 food pellets or per $5 \mathrm{~h}$, whichever came first.

After this, reinforcement was adjusted to a fixed-interval (FI) 1-min schedule, and after four 5-h sessions with this schedule in which water sometimes was and sometimes was not available, four experimental sessions were run in counterbalanced order. In two of the sessions (WET), the water bottles contained water for the whole 5-h session. In the others (DRINK-DRY), there was water in the bottle for only the first $5 \mathrm{~min}$ in each experimental hour, timed from the first lick. For the remainder of each hour, an empty bottle occupied the water bottle position. In all sessions, the food reinforcement schedule remained in effect without interruption. Both kinds of experimental session began with the filled water bottle in place. In DRINK-DRY sessions the bottle was replaced by an empty one 5-min after the first lick, and so on at the beginning of each hour.

\section{RESULTS}

Table 1 shows mean water intakes of each animal under the WET and DRINK-DRY experimental conditions, along with preexperimental control intakes averaged over five 5-h sessions in each of which subjects

Table 1

Water Intake (Milliliters) per 5-Hour Session

\begin{tabular}{cccc}
\hline & \multicolumn{3}{c}{ Condition } \\
\cline { 2 - 4 } Subject & WET & DRINK-DRY & Control \\
\hline A6 & 69.0 & 21.0 & 17.5 \\
A7 & 63.5 & 27.0 & 18.4 \\
A8 & 30.0 & 22.5 & 12.2 \\
A9 & 84.0 & 25.5 & 15.6 \\
Mean & 61.6 & 24.0 & 15.9 \\
\hline
\end{tabular}


were limited to 300 reinforcers for 300 barpresses (CRF). In both experimental situations, water intakes noticeably exceeded control levels, and maximum intakes occurred when water was available for the whole experimental session. However, comparing rates of drinking, the animals averaged $.21 \mathrm{ml}$ water intake per minute in WET sessions (water available for $300 \mathrm{~min}$ ) as against $.96 \mathrm{ml} / \mathrm{min}$ in DRINK-DRY sessions (water available for $25 \mathrm{~min}$ ).

Figure 1 illustrates the typical ways in which drinking occurred under each experimental condition. The figure shows cumulative licks at matched 5 -min periods in a WET and a DRINK-DRY experimental session. In Period 1, the first $5 \mathrm{~min}$ in each condition, drink durations were roughly equal; but thereafter, drink durations were regularly longer in 5-min periods that followed 55 min of water deprivation than in comparable periods in the WET condition. The ubiquity of this finding is illustrated in Figure 2, where drink durations averaged over matched WET and DRINK-DRY 5-min periods in all experimental sessions are shown separately for the individual animals. In all cases, approximately equal drinks occur in the first $5 \mathrm{~min}$ of each condition, and then the curves diverge, showing consistently longer drink durations under the DRINK-DRY than under the WET experimental condition for the whole of the $5-\mathrm{h}$ sessions.

Table 2 shows mean drink durations arranged according to bouts of drinking within the matched 5-min periods of WET and DRINK-DRY sessions. Subjects

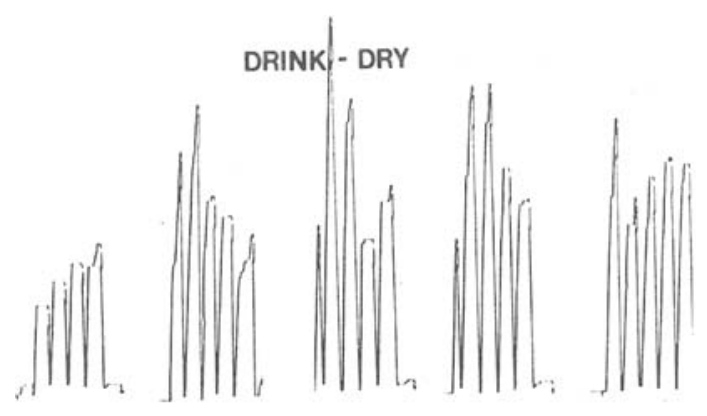

\section{PERIODS}

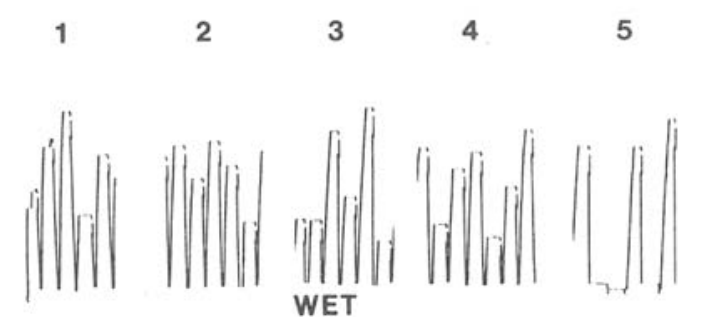

Figure 1. Matched 5-min segments of cumulative lick records during a WET and a DRINK-DRY session. Periods 1-5 include the first $5 \mathrm{~min}$ of each successive hour. Records are slightly longer than $5 \mathrm{~min}$ for the WET session to assure straddling of the matched DRINK-DRY period.

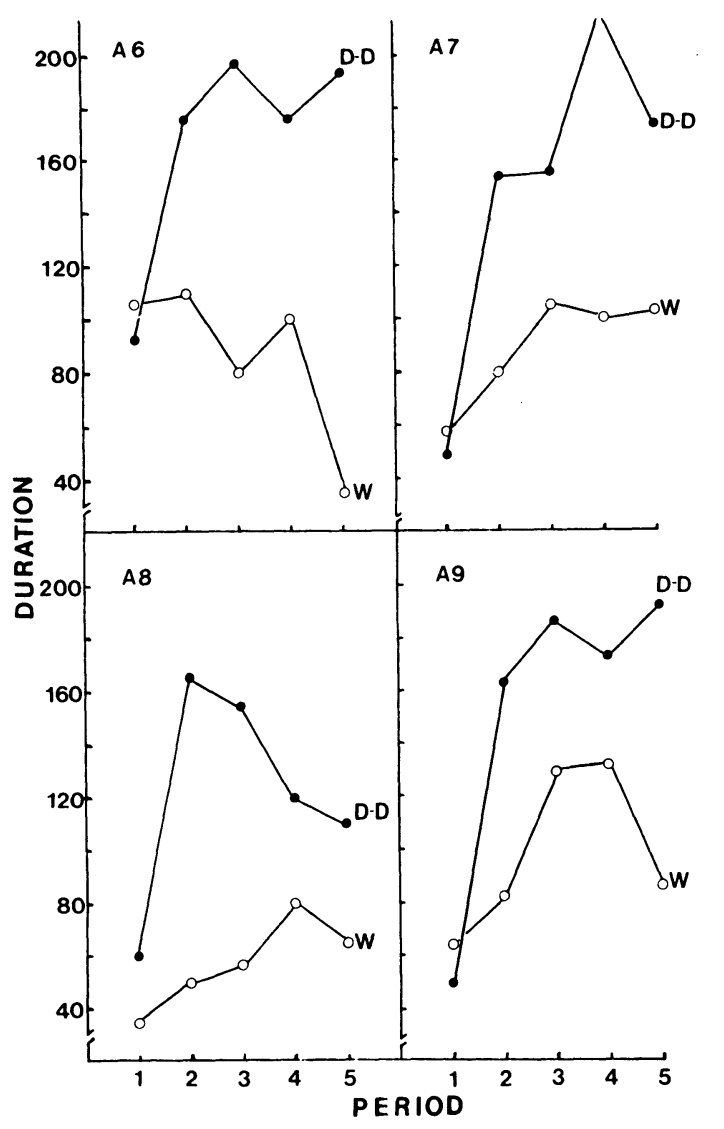

Figure 2. Mean drink durations over matched 5-min periods in WET and DRINK-DRY sessions for each animal. Values are means of two sessions under each condition.

could secure up to five food pellets in each period, and each pellet could be followed by a bout of drinking. These bouts are numbered 1 through 5 , and the durations of Bouts 1,2,3, and so on, averaged across periods are the entries in the table. Occasions when pellets were not followed by drinks (i.e., 0 -sec drink durations) were not included in the computations, so the means represent actual drinking times when drinks occurred. Durations of drinks were consistently longer under the DRINK-DRY than under the WET experimental condition. Successive bouts generally diminished in length under the DRINK-DRY but not under the WET condition, but the fifth DRINK-DRY bout still exceeded the duration of the first WET bout, on the average.

Despite the differences in amounts and rates of drinking under the WET and DRINK-DRY conditions, the rates at which the animals secured pellets of food hardly differed. Overall, the mean rates of pellet acquisition were 53.9 and 55.6 pellets per hour under the respective conditions, a nonsignificant difference. Over the 105 -min periods ( 2 sessions by 5 periods per session) in which water was available in DRINK-DRY sessions, Subjects A6 and A7 secured all possible food pellets (50), A8 missed 2, and A9 missed 1. In the matched periods of the WET session, A6 missed two pellets, 
Table 2

Mean Lengths (Seconds) of Drinking Bouts Within Matched 5-Min Periods of WET and DRINK-DRY Sessions

\begin{tabular}{lcccccc}
\hline & & \multicolumn{5}{c}{ Bout } \\
\cline { 3 - 7 } & & 1 & 2 & 3 & 4 & 5 \\
\hline \multirow{4}{*}{ DRINK- } & A6 & 29.7 & 41.0 & 35.5 & 32.0 & 29.5 \\
DRY & A7 & 32.2 & 48.3 & 34.4 & 26.9 & 27.8 \\
& A8 & 44.6 & 34.1 & 27.7 & 18.3 & 18.0 \\
& A9 & 46.5 & 33.8 & 29.9 & 32.1 & 32.6 \\
& Mean & 38.2 & 39.3 & 32.1 & 27.3 & 26.9 \\
& A6 & 25.0 & 22.1 & 25.7 & 22.8 & 19.2 \\
WET & A7 & 26.0 & 30.0 & 18.5 & 25.0 & 21.1 \\
& A8 & 17.0 & 13.3 & 13.7 & 16.6 & 13.0 \\
& A9 & 20.5 & 27.4 & 24.4 & 20.6 & 22.5 \\
& Mean & 22.1 & 23.2 & 21.0 & 21.2 & 18.9 \\
\hline
\end{tabular}

A7 missed one, and A9 missed none. Thus, for the periods in question, pellets were secured by all animals at close to the maximum rate under both conditions equally. However, every subject drank more frequently after pellets in the DRINK-DRY than in the WET condition: $\mathrm{A} 6,98 \%$ vs. $77 \%$; $\mathrm{A} 7,88 \%$ vs. $75 \%$; $\mathrm{A} 8,90 \%$ vs. $71 \%$; and $\mathrm{A} 9,97 \%$ vs. $86 \%$.

\section{DISCUSSION}

There are two ways of regarding schedule-induced polydipsia, one concerned with the quantity of water ingested (Falk, 1961), the other concerned with food-entrained drinking (Keehn \& Burton, 1978). These are not necessarily interchangeable dependent variables, because high intakes are possible with either occasional long draughts or with regular small food-entrained drinks. Quantity of drinking and frequency of drinking are highly correlated with the intermittent food reinforcement schedule that we employed (FI $1 \mathrm{~min}$ ), but the direction of regard affects how schedule-induced polydipsia is interpreted.

If quantity of water consumed is the direct consequence of intermittent feeding, then the relationship between rate of eating and rate of drinking is the important datum to seek. In this regard, rate of drinking is sometimes proportional to rate of feeding generated either by size (Staddon, 1977, Figure 2) or by frequency (Hawkins et al., 1972, Figure 5) of meals. From this standpoint, Cohen (1975) suggests that intermittent feeding makes drinking water reinforcing. On the other hand, if entrainment is the principal consequence of intermittent feeding, with volume ingested a dramatic by-product, then overall consumptions of food and water are less interesting than are particular correspondences beween a meal and a drink. From this view, Keehn and Riusech (1979) suggest that drinking water makes dry food pellets more reinforcing, just as mixing ingredients improves some foods.

When drinking is prevented entirely during intermittent food reinforcement, food-entrained drinking and the rate at which rats secure food both decline after some hours, in line with the view of Keehn and Riusech (1979). Partial availability prevents the decline in rate of eating and at the same time enhances the durations of drinks when they become possible. This is not a prediction from the Keehn and Riusech theory, but it is consistent with the general notion that intermittent feeding generates an abnormal need to drink. The amount of drinking is known to depend directly on presession food deprivation; the present study shows that it also depends on within-session deprivation of water.

\section{REFERENCES}

Brush, M. E., \& Schaeffer, R. W. Effects of water deprivation on schedule-induced polydipsia. Bulletin of the Psychonomic Society, 1974, 4, 69-72.

Coren, I. L. The reinforcement value of schedule-induced drinking. Journal of the Experimental Analysis of Behavior, 1975, 23, 37-44.

FALK, J. L. Production of polydipsia in normal rats by an intermittent food schedule. Science, 1961, 133, 195-196.

F ALK, J. L. Conditions producing psychogenic polydipsia. Annals of the New York Academy of Sciences, 1969, 157, 569-593.

FLORY, R. K. The control of schedule-induced polydipsia: Frequency and magnitude of reinforcement. Learning and Motivation, 1971, 2, 215-227.

FreED, E. X., \& Hymowitz, N. Effects of schedule, percent body weight and magnitude of reinforcer on acquisition of scheduleinduced polydipsia. Psychological Reports, 1972, 31, 95-101.

Hawkins, T. D., Schrot, J. F., Githens, S. H., \& Everett, P. B. Schedule induced polydipsia: An analysis of water and alcohol ingestion. In R. M. Gilbert \& J. D. Keehn (Eds.), Schedule effects: Drugs, drinking and aggression. Toronto: University of Toronto Press, 1972.

KеEнn, J. D. Schedule-induced polydipsia, schedule-induced drinking, and body weight. Bulletin of the Psychonomic Society, 1979, 13, 78-80.

KeEhN, J. D., \& Burton, M. Schedule-induced drinking: Entrainment by fixed and random interval schedule-controlled drinking. T-I-T Journal of Life Sciences, 1978, 8, 93-97.

Keenn, J. D., \& Colotra, V. A. Stimulus and subject control of schedule-induced drinking. Journal of the Experimental Analysis of Behavior, 1971, 16, 257-262.

KeEHN, J. D., \& RIUSECH, R. Schedule-induced drinking facilitates schedule-controlled feeding. Animal Learning \& Behavior, 1979, 7, 41-44.

KissilefF, H. R. Food-associated drinking in the rat. Journal of Comparative and Physiological Psychology, 1969, 67, 284-300.

Premack, D. Reinforcement theory. In D. Levine (Ed.), Nebraska symposium on motivation. Lincoln: University of Nebraska Press, 1965.

Rosenblith, J. Z. Polydipsia induced in the rat by a secondorder schedule. Journal of the Experimental Analysis of Behavior, 1970, 14, 139-144.

Staddon, J. E. R. Schedule-induced behavior. In W. K. Honig \& J. E. R. Staddon (Eds.), Operant behavior. New York: Prentice-Hall, 1977.

(Received for publication May 3, 1979.) 